\title{
Análise da fragilidade ambiental na bacia do rio Queima-Pé, Tangará da Ser- ra, MT
}

\author{
Rogerio Gonçalves Lacerda de GOUVEIA ${ }^{1}$, Edinéia Aparecida dos Santos GALVANIN², Sandra \\ Mara Alves da Silva NEVES ${ }^{2} \&$ Ronaldo José NEVES ${ }^{2}$
}

${ }^{1}$ Departamento de Engenharia Ambiental, Universidade de Uberaba. Av. Rondon Pacheco, 2000, Lídice, CEP 38.408-343, Uberlândia, MG, Brasil. E-mail: rglgouveia@gmail.com.

${ }^{2}$ Programa de Pós-graduação em Ambiente e Sistemas de Produção Agrícola, Universidade do Estado de Mato Grosso. Rod. MT 358, Km 07, Caixa Postal 287, CEP 78.300-000, Tangará da Serra, MT, Brasil. E-mail: galvaninbbg@unemat.br, ssneves@unemat. br; rjneves@unemat.br.

Recebido em 09/2013. Aceito para publicação em 06/2015.

Versão online publicada em 19/08/2015 (www.pesquisasemgeociencias.ufrgs.br)

\begin{abstract}
Resumo - 0 presente trabalho tem como objetivo analisar a fragilidade ambiental da bacia hidrográfica do Rio Queima-Pé, localizada no município de Tangará da Serra, estado de Mato Grosso (Centro-oeste, Brasil), para subsidiar ações de planejamento ambiental. Para a caracterização da área de estudo foram utilizadas cartas temáticas de geomorfologia, pedologia, pluviosidade, uso da terra e cobertura vegetal. A metodologia adotada foi operacionalizada com o software ArcGis da Esri. A bacia do Rio Queima-Pé apresenta $11 \%$ da área com fragilidade ambiental alta, em decorrência do uso da terra que oferece baixa proteção ao solo. Conclui-se que a utilização da terra com pastagens e cana de açúcar em solo argissolo merece atenção especial, pois estes apresentam alto teor de areia em sua composição, favorecendo a ocorrência de processos erosivos.

Palavras chave: fragilidade ambiental, geotecnologias, bacia hidrográfica.
\end{abstract}

\begin{abstract}
EnVironmental Fragility analysis in the Queima-PÉ RIVER basin, TANGará da SERRA, MT.
This study aims to analyze the environmental fragility of the Queima-Pé river basin, located in Tangará da Serra municipality in the Mato Grosso State (Midwestern, Brazil), to subsidize environmental planning actions. The study area was characterized using the following thematic maps: geomorphology, pedology, land use and vegetation cover, and rainfall. The methodology used was operationalized using ArcGis software of Esri. The Queima-Pé river basin present $11 \%$ of the area has high environmental fragility, mainly due to land use that provides little protection to the soil. We conclude that the land use with pasture and sugarcane in the argisoil soils deserve special attention because of the high sand content, which favors erosion.
\end{abstract}

Key words: environmental fragility, geotechnologies, hydrographic basin.

\section{Introdução}

Os estudos relativos às fragilidades dos ambientes são de extrema importância ao planejamento ambiental. A identificação dos ambientes naturais e suas fragilidades potenciais e emergentes proporcionam uma melhor definição das diretrizes e ações a serem implementadas no espaço físico-territorial. Tal identificação serve de base para o zoneamento e fornece subsídios à gestão do território (Spörl \& Ross, 2004).

Assim, fatores como o manejo inadequado do solo, o qual causa compactação, dificulta a infiltração de água da chuva e o escoamento de partículas de terra, causa processos erosivos e assoreamentos dos rios. A intensificação da precipitação pluviométrica em áreas com forte declividade desencadeia processos erosivos, tais como sulcos, cicatrizes de escorregamento, ou ainda ravinas e voçorocas ligadas às cabeceiras de drenagem que fragiliza o ambiente (Nakashima, 2001).

Ross (1994) considera que as unidades de fragilidade dos ambientes naturais devem ser resultantes dos levantamentos básicos de geomorfologia, solos, cobertura vegetal/uso da terra e clima. Esses elementos, tratados de forma integrada, possibilitam obter um diagnóstico das diferentes categorias hierárquicas da fragilidade dos ambientes naturais.

O descaso com o planejamento físico territorial resulta em impactos negativos, como a ocupação desordenada, que pode acarretar processos 
como: lixiviação, desmatamento, erosão e propensão à desertificação. Do ponto de vista econômico, pode ocorrer também a baixa produtividade das atividades agropecuárias, o que, por sua vez, afeta o próprio ser humano, que sofrerá as consequências dessas intervenções, numa relação de causa-efeito (Batista et al., 2009).

Nesse contexto, as geotecnologias oferecem diversas vantagens na gestão ambiental e territorial, a começar pela eficiência, precisão e qualidade da informação espacializada. Esta possui uma base de dados espaciais que possibilita armazenar, consultar, exibir, alterar e excluir informações georreferenciadas. Além disso, a informação espacializada permite criar cadastros, gerar relatórios, gráficos, processar informações, calcular áreas e realizar estudos temporais e simulações (Coelho, 2009).

Diversas pesquisas, no âmbito da geotecnologia, vêm sendo realizadas com o objetivo de identificar e analisar a evolução temporal do uso da terra em bacias hidrográficas, considerando as classes de atividades de natureza humana e de vegetação natural (Wang et al., 2010; Lopes et al., 2010; Abd El - Kaway et al., 2011). Essas pesquisas apresen- tam como vantagem precisão, rapidez e custo reduzido, quando operacionalizadas via geotecnologias.

A realização deste trabalho se justifica pela importância da bacia para o munícipio de Tangará da Serra, Mato Grosso, da qual a captação de água para o abastecimento da população urbana é advinda. Além disso pertence à bacia do Rio Sepotuba, a qual está inserida na Bacia do Alto Paraguai (BAP), que compõe a base do bioma Pantanal. Neste contexto, o objetivo deste trabalho é analisar a fragilidade ambiental na bacia hidrográfica do rio Queima-Pé (BHRQP) e gerar subsídios para ações de planejamento ambiental e ordenamento territorial.

\section{Materiais e métodos}

A área de estudo compreende a BHRQP com uma área de 15.684,24 hectares localizada entre as coordenadas $14^{\circ} 33^{\prime}$ a $14^{\circ}{ }^{\circ} 43^{\prime}$ de latitude Sul e 57ํ3' a 57ํ28' de longitude Oeste, no município de Tangará da Serra, Estado de Mato Grosso (Fig. 1).

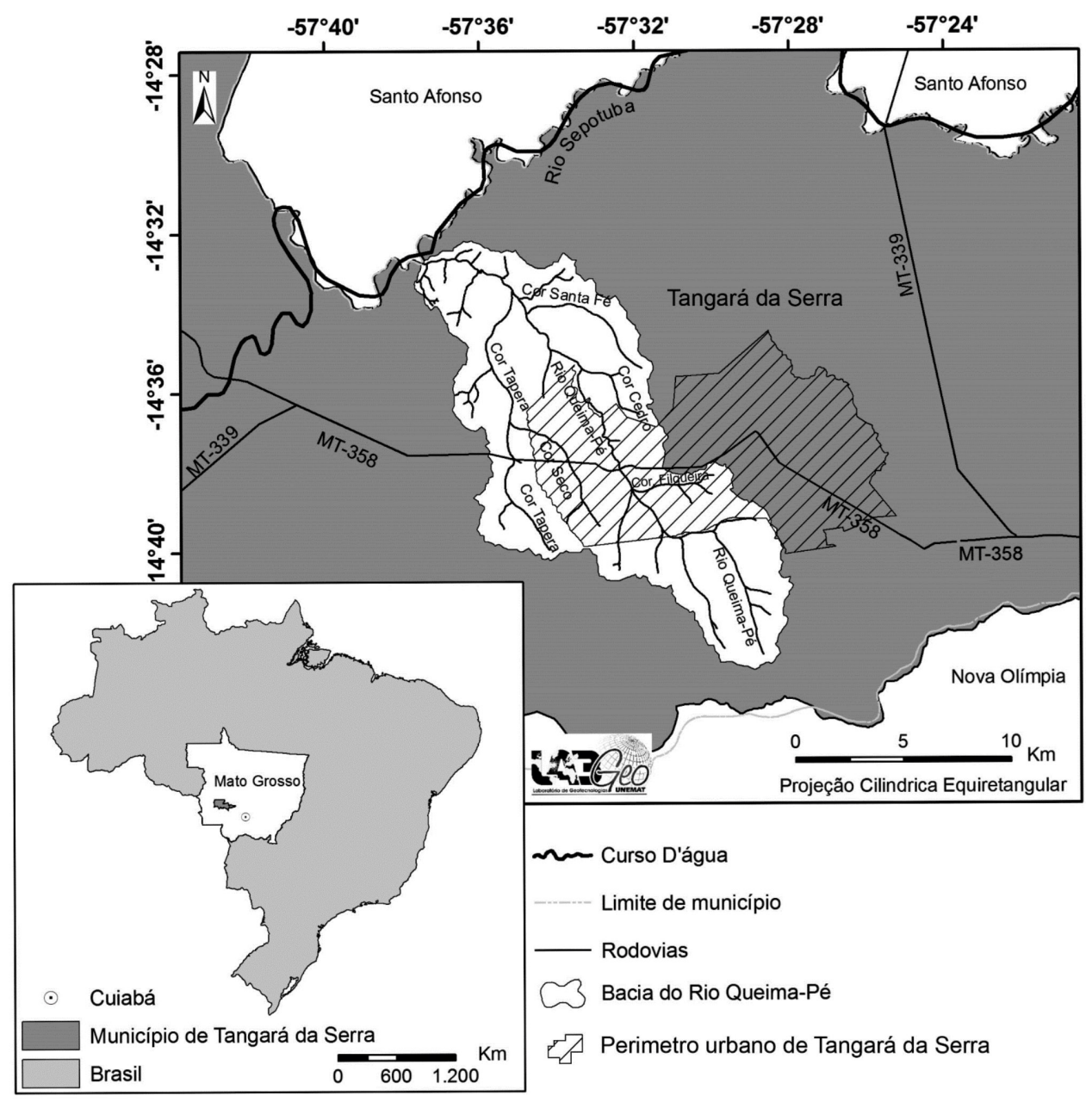

Figura 1. Localização da área de estudo. 
O clima da região de acordo com Köppen é o tropical úmido megatérmico (AW) ou seja quente semiúmido. Os valores médios anuais de temperatura, precipitação e umidade relativa do ar são, respectivamente, $24,4^{\circ} \mathrm{C}, 1.500 \mathrm{~mm}$ e $70-80 \%$ (Dallacort et al., 2010). As chuvas são concentradas no período de outubro a março (estação chuvosa), e entre abril e setembro estabelece-se a estação seca (IBGE, 2002). 0 acesso à área da bacia ocorre através das rodovias MT-358, MT-399 e MT-339.

\subsection{Procedimentos metodológicos}

Os dados de topografia do modelo digital de elevação (MDE) no formato raster foram coletados no banco de dados geomorfométrico do Brasil no projeto TOPODATA disponibilizado pelo Instituto Nacional de Pesquisas Espaciais (INPE). A delimitação vetorial do limite da bacia hidrográfica do Rio Queima-Pé foi realizada de forma automática através da extensão ArcHydro do software ArcGis 9.2.

Para a execução do estudo da fragilidade ambiental foi utilizada a combinação dos mapas de geomorfologia, pedologia e uso e cobertura da terra da BHRQP no Sistema de Informação Geográfica (SIG) (Fig. 2). No banco de dados geográficos foram inseridas informações das fragilidades de cada tema (mapas) e os dados das precipitações, apresentados nas tabelas 1, 2, 3 e 4 .

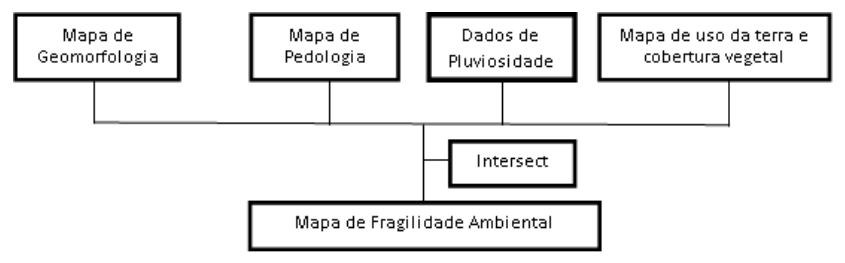

Figura 2. Esquema metodológico adotado no processo de avaliação da fragilidade ambiental.

Para a elaboração do mapa de uso da terra e cobertura vegetal na escala de 1:100.000 foram utilizadas as imagens ortorretificadas do satélite Geoeye, relativas às cenas po 772471-00, po 772471-10 e po 772471-20, com resolução radiométrica de 8 bits. A área imageada de cada cena é de $15,2 \mathrm{~km}$, com resolução espacial de $3 \mathrm{~m}$, datum WGS 84, datadas de agosto de 2011 (período da estiagem). A imagem foi recortada pela máscara, na extensão shapefile, da área de estudo.

A composição R (Red) G (Green) B (Blue) das imagens foi feita no software ArcGis da Esri, versão 9.2, através da ferramenta composite bands. Foi realizado o mosaico das cenas com a ferramenta mosaic to new raster presente no módulo arctoollbox do ArcGis. 0 processo de interpretação e classifica- ção da imagem de 2011 foi híbrido (segmentação por região + interpretação visual) para a geração do mapa de uso da terra na escala 1:100.000, no software ArcGis.

A nomenclatura das classes identificadas e as cores RGB da legenda estão de acordo com o manual técnico de uso da terra (Ibge, 2006). A validação do mapa gerado foi realizada por meio de cinco trabalhos de campo realizados no mês fevereiro de 2013 (período chuvoso) com o georreferenciamento dos locais visitados.

Os arquivos vetoriais dos mapas de geomorfologia e pedologia utilizados neste estudo foram gerados no âmbito do Plano de Conservação da Bacia do Alto Paraguai (PCBAP) do Ministério do Meio Ambiente (Brasil, 1997). Estes arquivos, no contexto desta pesquisa, foram recortados pela máscara da área de estudo e inseridos no Banco de Dados Geográficos, visando à integração com as demais informações alfanuméricas, a exemplo dos dados de precipitação.

A combinação das informações foi operacionalizada através da ferramenta Intersect do ArcGis, o que resultou no mapa de fragilidade ambiental. Cada uma das variáveis citadas foi hierarquizada em cinco classes de acordo com sua vulnerabilidade.

Dessa forma, tem-se a composição das relações destas quatro variáveis: Índices de Dissecação do Relevo - categoria hierárquica muito fraca (1) a muito forte (5); Solos - classes de fragilidade muito fraca (1) a muito forte (5); Uso da terra e Cobertura Vegetal - grau de proteção muito alto (1) a muito baixo/nulo (5); Pluviosidade - categoria hierárquica muito fraca (1) a muito forte (5), conforme proposto por Spörl \& Ross (2004).

Foi estabelecida uma classificação da fragilidade através da combinação entre os dígitos numéricos dos quatro planos de informação (Ex.: $111,121,234,342,555)$. Nessa convenção, o conjunto numérico 111 representa todas as variáveis favoráveis (fragilidade muito baixa), e o conjunto numérico 555 apresenta todas as variáveis desfavoráveis (fragilidade muito forte).

Segundo os procedimentos técnicos operacionais desse modelo, a variável Índice de Dissecação do Relevo ( $1^{\circ}$ dígito) do tema geomorfologia é que vai determinar o grau de fragilidade de cada área analisada. As demais variáveis irão definir uma hierarquização através de seus coeficientes de fragilidade, de modo que a variável Cobertura Vegetal irá identificar, por meio de seus índices, as áreas em que o equilíbrio dinâmico foi rompido, o que propicia situações de risco e as áreas em que a estabilidade permanece até o momento (Spörl \& 
Ross, 2004).

O Índice de Dissecação do Relevo considera o entalhamento médio dos vales e está baseado em informações da dimensão interfluvial média, nas colunas horizontais e entalhamento médio dos vales nas colunas verticais. A classificação varia de muito grande, grande, média, pequena e muito pequena de acordo com a tabela 1.

Tabela 1. Matriz dos índices de dissecação do relevo (fonte: Ross, 1994).

\begin{tabular}{lccccc}
\hline Dimensão Interfluvial & Muito Grande & Grande & Média & Pequena & \multicolumn{2}{c}{ Muito Pequena } \\
Média (Classes)/ & -1 & -2 & -3 & -4 & -5 \\
\cline { 2 - 6 } Entalhamento Médio & $>3750 \mathrm{~m}$ & $1750 \mathrm{~m} \mathrm{a}$ & $750 \mathrm{~m} \mathrm{a}$ & $250 \mathrm{~m} \mathrm{a}$ & $<250 \mathrm{~m}$ \\
Dos Vales (Classes) & & $3750 \mathrm{~m}$ & $1750 \mathrm{~m}$ & $750 \mathrm{~m}$ & \\
\hline Muito Fraco (1) < 20 m & 11 & 12 & 13 & 14 & 15 \\
Fraco (2) 20 a $40 \mathrm{~m}$ & 21 & 22 & 23 & 24 & 23 \\
Médio (3) 40 a $80 \mathrm{~m}$ & 31 & 32 & 33 & 34 & 35 \\
Forte (4) 80 a 160 m & 41 & 42 & 43 & 44 & 45 \\
Muito Forte (5) $>160 \mathrm{~m}$ & 51 & 52 & 53 & 54 & 55 \\
\hline
\end{tabular}

O entalhamento médio dos vales varia de acordo com o comprimento de rampa e o grau de declive, aqui tratados como dimensão interfluvial média e grau de entalhamento dos talvegues, a partir do modelo de dissecação do relevo. 0 processo erosivo (impacto da gota de chuva) irá influenciar na extensão que a água vai se deslocar em relação à parte mais rebaixada do terreno e da declividade da vertente. Quanto maior a distância percorrida, maior a velocidade do fluxo e, consequentemente, maior a capacidade de arraste de partículas.

Considerando-se a declividade da vertente, quanto mais declivosa maior será a velocidade do fluxo o que ocasionará maior capacidade de erosão (Devicari, 2009). Para o estabelecimento dos critérios utilizados para o tema solo, foram consideradas as variáveis: características de profundidade e espessuras dos horizontes superficiais e subsuperficiais, grau de coesão das partículas, plasticidade, estrutura e textura (Tab. 2).

De acordo com o tipo da cobertura vegetal é possível estabelecer a capacidade de proteção que cada cobertura proporciona. Na tabela 3, são apresentadas as fitofisionomias de vegetação de acordo com Ross (1994).

Tabela 2. Classes de fragilidade em decorrência do tipo de solo (Lvef = Latossolo vermelho eutroférrico; Lvdf = Latossolo vermelho distroférrico; Lvd = Latossolo vermelho escuro distrófico; Pvad = Argissolo Vermelho-Amarelo distrófico).

\begin{tabular}{lllc}
\hline Legenda & Tipos de solo & Classe & Código de fragilidade \\
\hline Lvd & Latossolo vermelho escuro distrófico & Baixa & 2 \\
Lvdf & Latossolo vermelho distroférrico & Baixa & 2 \\
Lvef & Latossolo vermelho eutroférrico & Baixa & 2 \\
Pvad & Argissolo Vermelho-Amarelo distrófico & Forte & 4 \\
\hline
\end{tabular}

Tabela 3. Graus de proteção por tipos de cobertura vegetal (fonte: Ross, 1994).

\begin{tabular}{|c|c|c|}
\hline Tipos de Cobertura Vegetal & $\begin{array}{c}\text { Grau de } \\
\text { Proteção }\end{array}$ & Código de fragilidade \\
\hline Florestas/ Matas Naturais/ Florestas Cultivadas com biodiversidade & Muito Alta & 5 \\
\hline $\begin{array}{l}\text { Formacõoes arbustivas naturais com extrato herbáceo denso mata } \\
\text { secundária, capoeira densa, pastagem cultivada com baixo pisoteio, cultivo } \\
\text { de ciclo longo como o cacau }\end{array}$ & Alta & 4 \\
\hline $\begin{array}{l}\text { Cultivo de ciclo longo em curvas de nível, pastagem com baixo pisoteio, } \\
\text { silvicultura de eucalipto com sub bosques de nativa }\end{array}$ & Média & 3 \\
\hline $\begin{array}{l}\text { Cultivo de ciclo longo em baixas densidades café, laranja com solo exposto } \\
\text { entre ruas, culturas de ciclo curto arroz, soja e milho com cultivos em } \\
\text { curva de nível }\end{array}$ & Baixa & 2 \\
\hline $\begin{array}{l}\text { Área desmatada e queimada recentemente, solo exposto por gradeação, } \\
\text { ao longo de caminhos e estradas, terraplagem, culturas de ciclo curto sem } \\
\text { práticas conservacionistas }\end{array}$ & Muito Baixa & 1 \\
\hline
\end{tabular}


Os níveis hierárquicos relativos as precipitações foram definidos de acordo com a maior ou a menor intensidade do efeito pluviométrico sobre os processos morfodinâmicos, obedecendo-se a uma hierarquização de ordem crescente quanto à capacidade de interferência da estabilidade do sistema. A tabela 4 apresenta os níveis de fragilidade dos comportamentos pluviométricos.

0 resultado derivado das combinações dos diferentes níveis de fragilidades das variáveis em ambiente SIG pertencentes aos temas apresentados é um produto cartográfico síntese, acompanhado de uma matriz ambiental, que identifica manchas de diferentes padrões de fragilidade. Essa situação possibilita mensurar qualitativamente as intervenções de natureza humana na área de estudo de acordo com a fragilidade a que o ambiente está exposto.

Tabela 4. Níveis hierárquicos dos comportamentos pluviométricos (fonte: Neves, 2006).

\begin{tabular}{|c|c|c|}
\hline Critérios de análise & $\begin{array}{l}\text { Níveis } \\
\text { hierárquicos }\end{array}$ & Código de fragilidade \\
\hline $\begin{array}{l}\text { Situação pluviométrica com distribuição regular ao longo do ano e com } \\
\text { volumes anuais não muito superiores a } 1000 \mathrm{~mm} / \mathrm{a}\end{array}$ & Muito Baixa & 1 \\
\hline $\begin{array}{l}\text { Situação pluviométrica com distribuição regular ao longo do ano e com } \\
\text { volumes anuais superiores a } 2000 \mathrm{~mm} / \mathrm{a} \text {. }\end{array}$ & Baixa & 2 \\
\hline $\begin{array}{l}\text { Situação pluviométrica com distribuição anual desigual, com } \\
\text { períodos secos entre } 2 \text { a } 3 \text { meses no inverno e no verão com maiores } \\
\text { intensidades de dezembro a março. }\end{array}$ & Média & 3 \\
\hline $\begin{array}{l}\text { Situação pluviométrica com distribuição anual desigual, com período } \\
\text { seco de } 3 \text { a } 6 \text { meses e alta concentração das chuvas no verão entre } \\
\text { novembro e abril quando ocorrem de } 70 \text { a } 80 \% \text { do total das chuvas. }\end{array}$ & Forte & 4 \\
\hline $\begin{array}{l}\text { Situação pluviométrica com distribuição regular, ou não, ao longo } \\
\text { do ano, com volumes grandes anuais, superiores a } 2500 \mathrm{~mm} / \mathrm{a} \text {; ou } \\
\text { ainda, comportamentos pluviométricos irregulares ao longo do ano, } \\
\text { com episódios de chuvas de alta intensidade e volumes anuais baixos, } \\
\text { geralmente inferiores a } 900 \mathrm{~mm} / \mathrm{a} \text { (semi-árido) }\end{array}$ & Muito Forte & 5 \\
\hline
\end{tabular}

\section{Resultados}

A fragilidade alta, com área total de $11 \%$, foi encontrada na dissecação de relevo fraca, porém os solos argissolos com textura média arenosa propicia a erosão aliada com intervenção humana, tais como: construção rural, lavoura permanente e temporária e pastagem, com baixo grau de proteção da terra. A classe com média fragilidade ambiental, presente em $77,07 \%$ da área investigada, encontra-se em locais com índice de dissecação do relevo com classificação muito fraca e fraca, com a presença de todos os tipos de latossolos e com intervenções de natureza humana classificadas como de baixa proteção ao solo, tais como áreas de mineração e áreas queimadas.

Os latossolos apresentam características físicas, químicas e biológicas propícias para a produção agrícola. Porém, para que essa fertilidade não seja exaurida no decorrer dos anos, torna-se necessária a adoção de técnicas de rotação de cultura e de plantio direto para a manutenção das atividades da macrofauna e da flora do solo.

Os espaços de baixa fragilidade ambiental, que correspondem a 11,93\% da área de estudo, encontram-se sob o índice de dissecação do relevo muito fraco e fraco, presente em todos os tipos de solo e recobertos por vegetação natural e massas d'água.
Os entalhamentos médios dos vales encontrados foram de até $20 \mathrm{~m}$ classificado como muito fraco (1), a fraco (2) entre 20 a $40 \mathrm{~m}$. A dimensão interfluvial média verificada é grande (2), ou seja, os cursos dos rios possuem distância entre 1750 a $3750 \mathrm{~m}$.

A figura 3 apresenta a distribuição geográfica dos quatro tipos de solos presente na BHRQP. $\mathrm{O}$ argissolo vermelho-amarelo distrófico (Pvad) encontra-se ao norte; o latossolo vermelho eutroférrico (Lvef) é a maior classe presente e ocorre no norte, centro, leste, oeste e uma parte no sul; o latossolo vermelho escuro distrófico (Lvd) é a menor classe presente, encontrado no leste; e o latossolo vermelho distroférrico (Lvdf) ocorre na parte sul.

A figura 4 mostra a espacialização das unidades do relevo, divididas em relevo de topo tabular, com grau de entalhamento dos vales menores de $20 \mathrm{~m}$, presente no centro sentido sul; o relevo de topo tabular, com grau de entalhamento dos vales entre 20 a $40 \mathrm{~m}$, presente no centro sentido norte da bacia.

A BHRQP possui 11.372,42 hectares de solo latossolo vermelho eutroférrico o qual ocupa a maior área da BHRQP. 0 argissolo vermelho-amarelo distrófico está presente em 2.213,23 hectares. Já o latossolo vermelho distroférrico em 2.057,08 hectares e o latossolo vermelho escuro distrófico em 41,51 hectares da bacia (Tab. 5). 
Tabela 5. Distribuição do uso e cobertura da terra em relação a forma dos topos do relevo e os tipos de solo (DT $12=$ dissecação do terreno (muito fraco); DT 22 = dissecação do terreno (fraco); Lvef = Latossolo vermelho eutroférrico; Lvdf = Latossolo vermelho distroférrico; Lvd = Latossolo vermelho escuro distrófico; Pvad = Argissolo Vermelho-Amarelo distrófico).

\begin{tabular}{|c|c|c|c|c|c|c|c|c|}
\hline \multirow{3}{*}{$\begin{array}{l}\text { Classes de uso e } \\
\text { cobertura vegetal }\end{array}$} & \multicolumn{8}{|c|}{ Áreas em hectares ocupadas pelas variáveis } \\
\hline & \multicolumn{3}{|c|}{ DT 12} & \multirow[b]{2}{*}{ Pvad } & \multicolumn{4}{|c|}{ DT 22} \\
\hline & Lvef & Lvdf & Lvd & & Lvef & Lvdf & Lvd & Pvad \\
\hline Áreas de mineração & 23,23 & - & - & - & - & - & - & - \\
\hline Áreas Queimadas & 100,49 & - & - & - & - & - & - & - \\
\hline Construção Rural & 94,28 & 32,80 & - & - & 64,46 & - & - & 20,13 \\
\hline Influência Urbana & 544,70 & 2,91 & 39,13 & - & 24,05 & - & 1,41 & - \\
\hline Lavoura Permanente & 9,77 & 2,48 & - & - & 19,16 & - & - & - \\
\hline Lavoura Semiperene & $1.344,39$ & 740,92 & - & - & 291,40 & - & - & 0,38 \\
\hline Lavoura Temporária & 633,97 & 851,79 & - & - & 179,39 & - & - & 13,65 \\
\hline Massas d'água & 61,50 & 8,28 & - & 0,02 & 17,85 & - & - & 4,01 \\
\hline Pastagem & $3.465,18$ & 264,30 & - & - & $3.335,80$ & - & - & $1.690,89$ \\
\hline Vegetação Natural & 231,83 & 66,16 & 0,97 & - & 479,76 & - & - & 396,14 \\
\hline Vegetação Ciliar & 241,30 & 76,19 & - & - & 118,85 & - & - & 85,88 \\
\hline Silvicultura & 89,55 & 11,25 & - & - & 1,51 & - & - & 2,13 \\
\hline Total & $6.840,19$ & $2.057,08$ & 40,10 & 0,02 & $4.532,23$ & - & 1,41 & $2.213,21$ \\
\hline
\end{tabular}

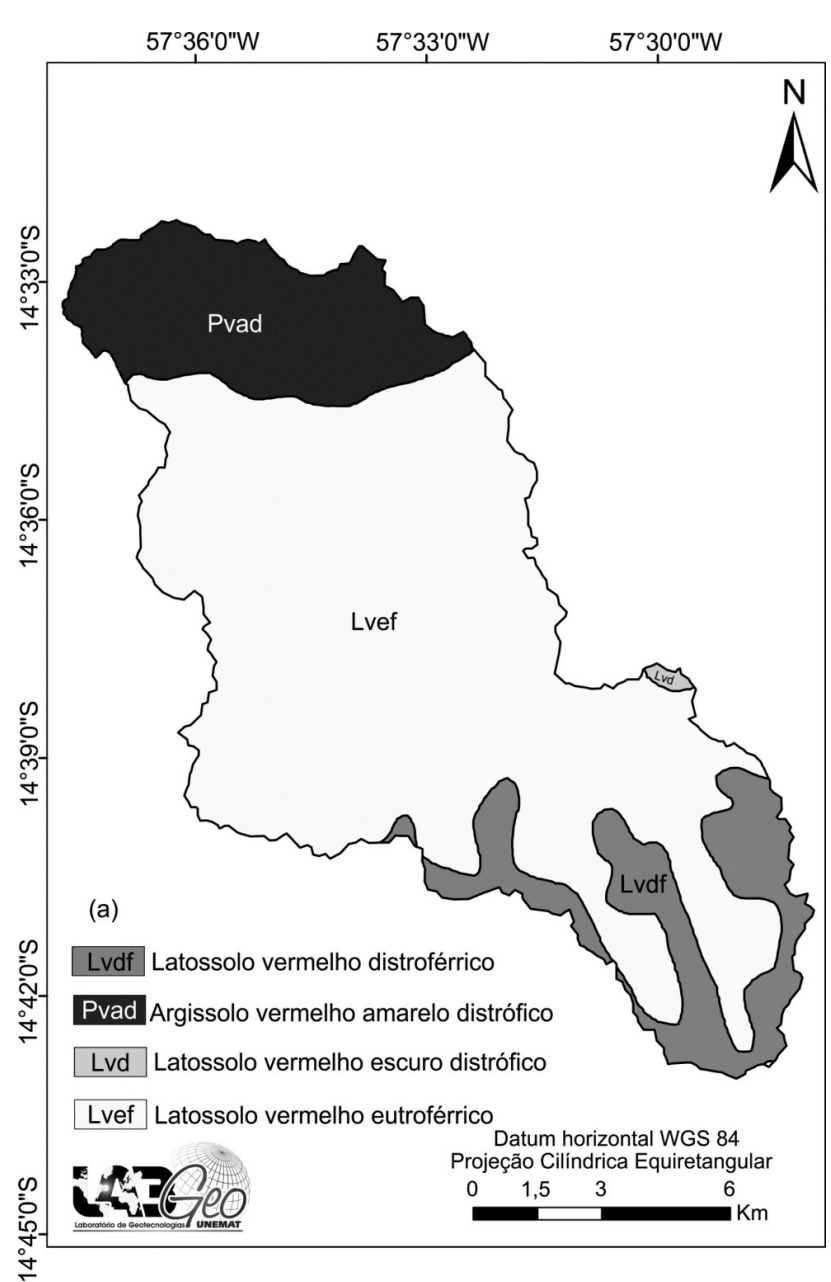

Figura 3. Mapa de pedologia da área de estudo.

0 argissolo vermelho-amarelo distrófico (Pvad) se concentra ao norte da BHRQP conforme ilustrado na figura 3, ocupando $14,12 \%$ da área (Tab. 5). Suas características são perfil A moderado, textura média/argilosa e relevo forte ondulado

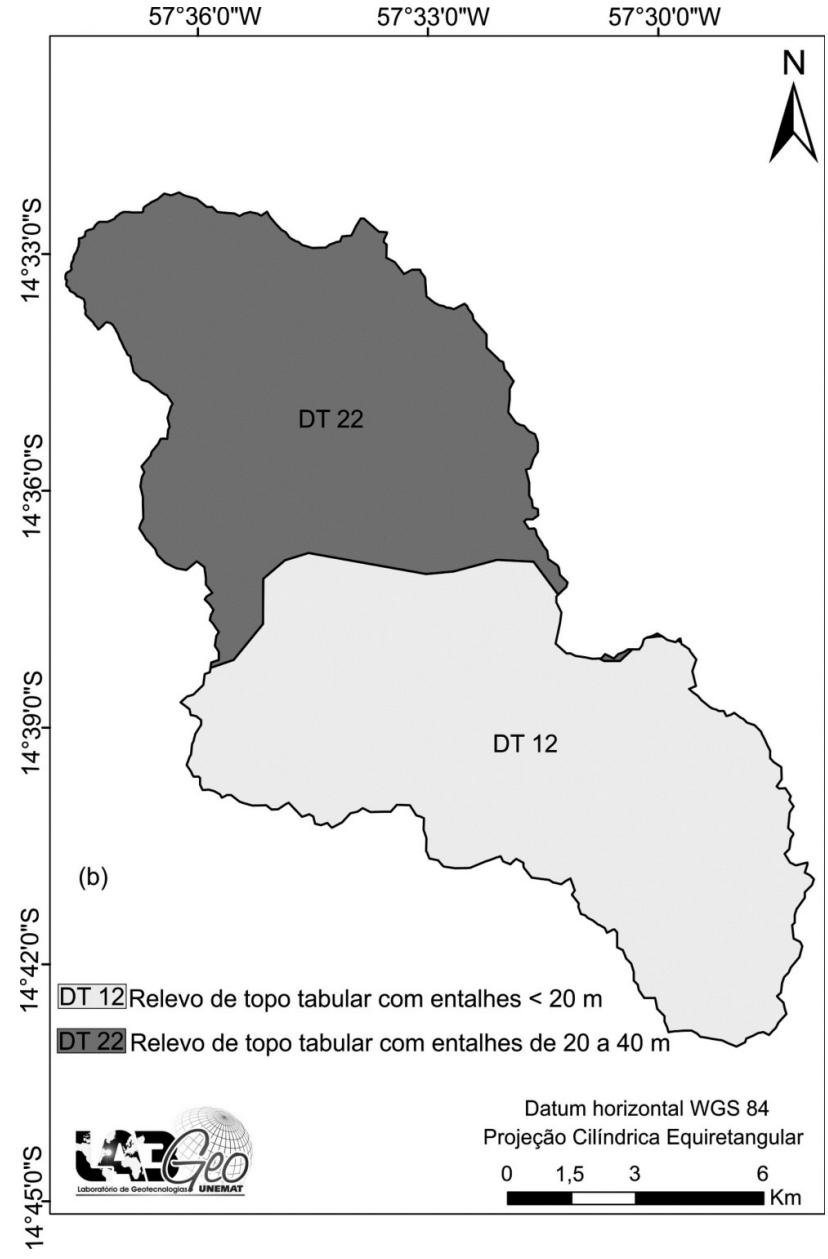

Figura 4. Mapa de geomorfologia da BHRQP.

(Embrapa, 1999).

As dissecações de relevo encontradas na BHRQP se referem às formas do relevo, tabulares com diferentes ordens de grandeza de aprofundamento de drenagem separado por vales de fundo plano. 
0 grau de entalhamento dos vales menores de 20 $\mathrm{m}$, considerados muito fracos (DT 12), ocorre na parte central estendendo-se para o sul da bacia. As formas de relevo de topo tabulares com diferentes ordens de grandeza de aprofundamento de drenagem são separadas por vales de fundo plano. 0 grau de entalhamento dos vales varia entre 20 a 40 $\mathrm{m}$, considerado fraco (DT 22) e ocorrem na parte central em direção norte da bacia, como pode ser visualizado na figura 4 .

Na figura 6, que mostra a distribuição da fragilidade ambiental da BHRQP, pode-se observar que toda a extensão da parte norte da bacia apresenta o relevo com baixo grau de fragilidade de acordo com a forma do topo do relevo tabular fraca (DT 22), com vales de entalhe fraco. Os tipos de solo argissolo vermelho-amarelo distrófico (Pvad), com textura médio/argiloso, necessita de alguns procedimentos de conservação para evitar possíveis processos erosivos causados por atividades agropecuárias.

A figura 5 mostra o uso da terra e a cobertura vegetal presente na BHRQP e a figura 6 a fragilidade ambiental da BHRQP.

A região central da bacia apresenta dois ín-

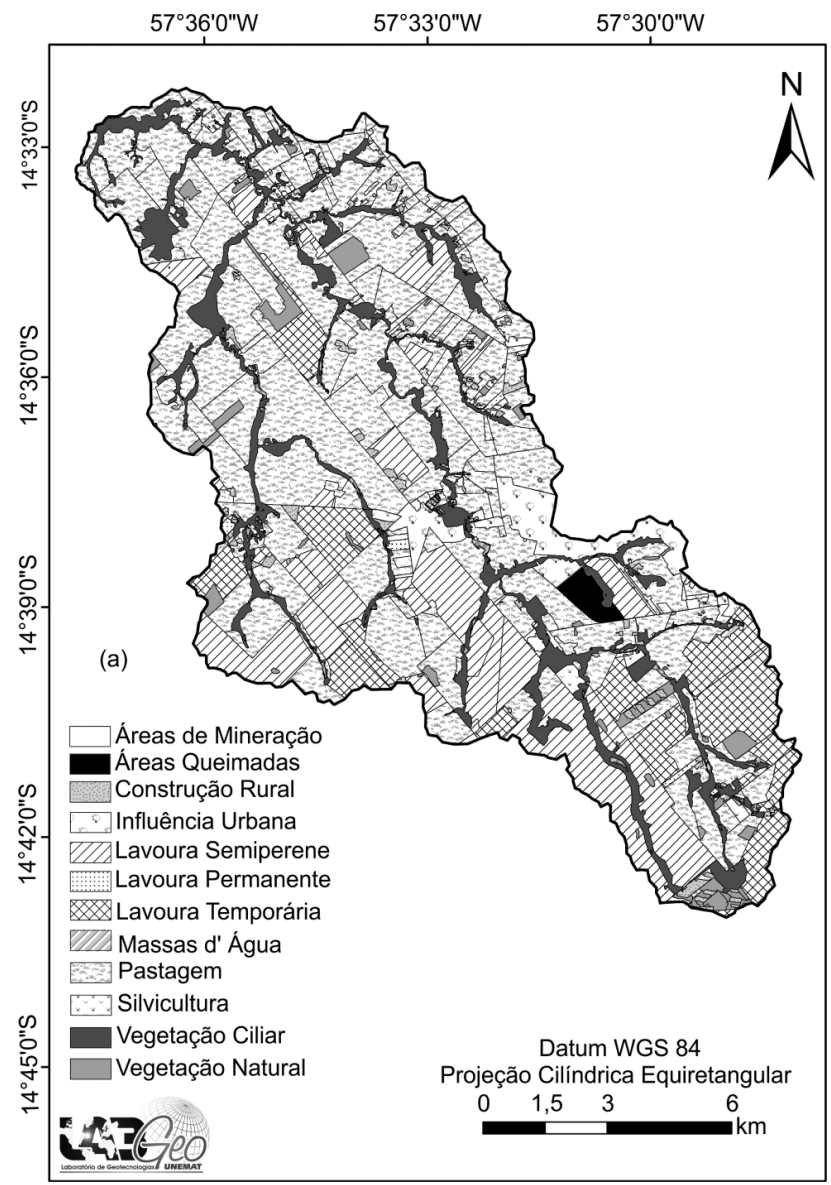

Figura 5. Classes de uso da terra e cobertura vegetal da BHRQP. dices de dissecação do relevo, sendo ocupada por latossolo vermelho eutroférrico (Lvef) que apresenta baixo grau de fragilidade ambiental. Porém, a intervenção humana, como área queimada, construção rural, influência urbana, lavouras e pastagem, que não oferecem proteção a terra, podem, ao longo do tempo, alterar toda a paisagem local; por isso a região foi classificada como de média fragilidade ambiental.

Na parte sul da BHRQP ocorre a forma de relevo tabular, com dissecação muito fraca (DT 12), e latossolos vermelho distroférrico (Lvdf), que são estáveis em função da textura argilosa, profundos e bem drenados. Mas, as intervenções antrópicas, como lavouras e pastagem, podem alterar seu equilíbrio, sendo, essa área classificada como de média fragilidade ambiental.

A mata ciliar e a silvicultura por serem classificadas como de alta proteção à terra e presente em todos os solos da BHRQP, consequentemente em todas as formas encontradas de dissecação do relevo, apresenta fragilidade ambiental baixa.

Na tabela 6 é mostrado o grau de fragilidade ambiental da área de estudo de acordo com as variáveis analisadas: índice de dissecação do relevo,

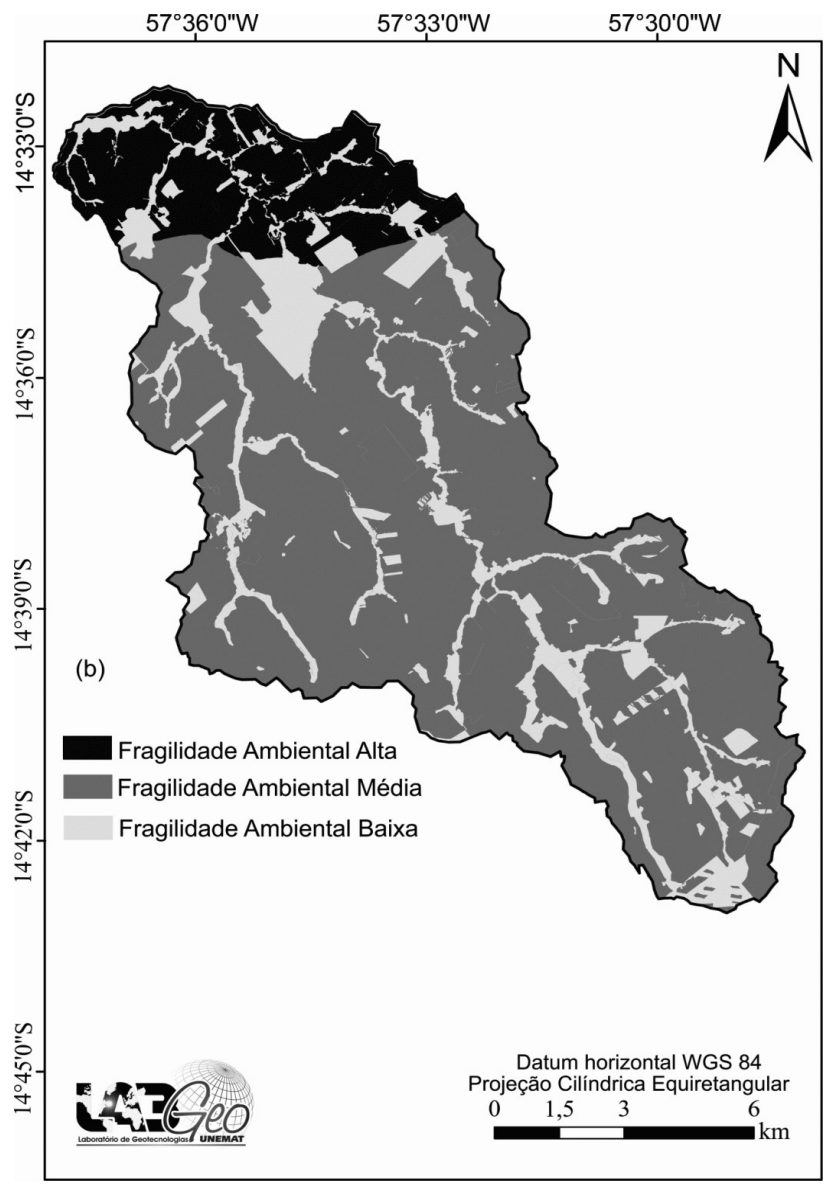

Figura 6. Mapa de fragilidade ambiental. 
Tabela 6. Grau de fragilidade de acordo com as variáveis encontradas na área de estudo.

\begin{tabular}{lcccc|cccc}
\hline Classes de uso da terra e cobertura & \multicolumn{4}{c|}{ DT 12 } & \multicolumn{3}{c}{ DT 22 } \\
\cline { 2 - 8 } vegetal & Lvef & Lvdf & Lvd & Pvad & Lvef & Lvdf & Lvd & Pvad \\
\hline Áreas degradadas por mineração & Forte & - & - & - & - & - & - & - \\
Áreas queimadas & Forte & - & - & - & - & - & - & - \\
Construção rural & Médio & Médio & - & - & Médio & - & - & Forte \\
Influência urbana & Médio & Médio & Médio & - & Médio & - & Médio & - \\
Lavoura permanente & Médio & Médio & - & - & Médio & - & - & Forte \\
Lavoura semiperene & Médio & Médio & - & - & Médio & - & - & Médio \\
Lavoura temporária & Médio & Médio & - & - & Médio & - & - & Forte \\
Massas d'água & Médio & Médio & - & Fraco & Médio & - & - & Fraco \\
Pastagem & Médio & Médio & - & - & Médio & - & - & Forte \\
Vegetação ciliar & Fraco & Fraco & Fraco & - & Fraco & - & - & Fraco \\
Vegetação natural & Fraco & Fraco & - & - & Fraco & - & - & Fraco \\
Silvicultura & Fraco & Fraco & - & - & Fraco & - & - & Fraco \\
\hline
\end{tabular}

o tipo de solo e o uso e cobertura da terra. A área queimada, que apresenta forte grau de fragilidade ambiental, ocorreu no latossolo vermelho eutroférrico em dois tipos de relevo, um com vales de entalhe muito fraco a fraco e outro no relevo com vales de entalhe fraco.

As construções rurais existentes na área de estudo estão situadas em latossolos vermelho eutroférrico no relevo com vales de entalhe muito fraco a fraco e também nos latossolo eutrófico e argissolo com vales de entalhe fraco, o que configura média fragilidade ambiental, porém o uso da terra para construções rurais apresenta baixa proteção ao solo (Tab. 6).

A cobertura vegetal de mata ciliar foi a única classe presente em todos os tipos de solo e índices de dissecação do relevo, caracterizando baixa fragilidade ambiental nos locais de sua ocorrência na área de estudo, pois sua faixa de predominância oferece alta proteção ao solo (Fig. 5).

A classe de influência urbana concentra-se sob latossolo vermelho eutroférrico, latossolo vermelho distroférrico e latossolo vermelho escuro distrófico, em relevo cujos vales são: de entalhe muito fraco a fraco e de entalhe fraco, apresentando fragilidade média.

A classe pastagem recobre o latossolo vermelho eutroférrico e distroférrico e os relevos de entalhes fraco a muito fraco e fraco, sendo a maior classe de uso da terra nos solos argissolo. A maior parte da pastagem encontra-se em estágio de degradação avançado, o que caracteriza um forte grau de fragilidade ambiental.

\section{Discussão dos resultados}

O uso da terra por intervenções de natureza humana possibilita um grau médio a baixo de pro- teção ao solo, que contribui para a classificação de fragilidade ambiental alta (Santos et al., 2010).

Essas áreas merecem atenção especial pelo uso da terra e cobertura vegetal, principalmente com relação ao uso desenfreado de técnicas como o plantio convencional, preparo da terra com auxílio de tratores, plantios sem curva de nível e as erosões nos cursos dos rios provocadas pelo gado (Oliveira et al., 2012).

Toda área ocupada por latossolo encontra-se sob influência urbana e são de médio grau de fragilidade, mesmo apresentando galerias pluviais de escoamento da chuva e construções de acordo com o perfil topográfico, a cobertura existente não protege o solo.

0 latossolo vermelho distroférrico (Lvdf) está presente em 13,11\% da área, que apresenta alta saturação por bases, textura muita argilosa e ocorre em relevo plano suavemente ondulado, apto para mecanização e risco baixo de erosão (Embrapa, 1999). O latossolo vermelho eutroférrico (Lvef) encontra-se distribuído em 72,50\% da área total da BHRQP (Tab. 5) e caracteriza-se por textura argilosa, com perfil A moderado e relevo praticamente plano, solos profundos com boa drenagem, com capacidade de retenção de água resistência à erosão e alta fertilidade, considerado bom para a prática de mecanização agrícola (Reis et al., 2004). A maior parte deste solo está ocupada por pastagens e todos os tipos de lavouras devido a alta fertilidade natural do solo e sua topografia ser plana.

0 argissolo apresenta alta capacidade de sofrer erosão laminar, favorecendo a erosão. Para prevenir o aparecimento de erosão, a adoção de técnicas conservacionistas se faz necessário pois evita a degradação ambiental (Farinasso et al., 2006).

A utilização de queimada para limpeza de áre- 
as é uma prática comum, porém elimina a vegetação presente, fragilizando a resistência dos solos em relação às águas pluviais, favorecendo os processos erosivos (Machado, 2012).

A cana-de-açúcar recobre os latossolos vermelho eutroférrico e distroférrico, no relevo com vales de entalhe muito fraco a fraco e latossolo vermelho eutroférrico e argissolo, com vales de entalhe fraco. Por ser uma cultura semiperene de baixa densidade foi classificada como de forte risco de fragilidade ambiental (Ross, 1994). Resultado semelhante foi encontrado por Pessoa et al. (2013) que, ao estudar o uso da terra na interbacia do Rio Paraguai Médio (MT), observaram que a vegetação nativa estava presente em toda a bacia, apesar de sofrer redução de 22,89 \% da área com a ocupação por pastagem e cana de açúcar no período de 20 anos.

Os latossolos apresentam perfis de solo mais profundos propícios à infiltração da água de precipitação, localizados em áreas com declividade baixa a média, com influência urbana, sendo então classificada como área de grau de fragilidade médio (Massa \& Ross, 2012).

\section{Conclusão}

Na bacia hidrográfica do Rio Queima-Pé a fragilidade ambiental forte está presente na porção norte da bacia em argissolos, que por serem mais arenosos necessitam para sua utilização e/ou ocupação de cuidados e técnicas de conservação ambiental.

A fragilidade média ocorre na maior parte da bacia, embora a área onde ocorra apresente índice de dissecação do relevo muito fraco e fraco e a presença de vários tipos de latossolos. Essa fragilidade pode evoluir para forte, devido à presença de pastagens degradadas, acesso de bovinos aos cursos dos rios provocando erosão em barrancos, plantio convencional da agricultura expondo o solo e falta de curva de nível.

Em áreas de vegetação natural, mata ciliar e silvicultura a fragilidade ambiental é fraca. Por fim, o tipo de uso da terra na bacia está relacionado com a dinâmica de ocupação, necessitando de monitoramento, considerando que a fragilidade pode ser alterada por intervenção humana.

Agradecimentos- Os autores agradecem à CAPES, pelo apoio em forma de bolsas de mestrado, sendo uma delas vinculada ao projeto de pesquisa "Modelagem de indicadores ambientais para a definição de áreas prioritárias e estratégicas à recuperação de áreas degradadas da região sudoeste de Mato Grosso/MT", vinculado à subrede de estudos sociais, ambientais e de tecnologias para o sistema produtivo na região sudoeste mato-grossense - REDE ASA, financiada no âmbito do Edital MCT/CNPq/FNDCT/FAPs/ MEC/CAPES/PRO-CENTRO-OESTE № 031/2010.

\section{Referências}

Abd El - Kaway, O.R., Rod, J.K. \& Suliman, A.S. 2011. Land use and land cover change detection in the western Nile delta of Egypt using remote sensing data. Journal Apllied Geography, 31: 483-494.

Batista, A.N.C., Almeida, N.V. \& Melo, J.A.B. 2009. Utilização de imagens CBERS no diagnóstico do uso e ocupação do solo na microbacia do riacho Maracajá, Olivedos, PB. Caminhos de Geografia, 10(32): 235- 244.

Brasil. 1997. Plano de Conservação da Bacia do Alto Paraguai (Projeto Pantanal). Ministério do Meio Ambiente. Diagnóstico dos meios Físico e Biótico. Brasília/DF: PNMA, v. 2, n. 1, p. 283-300.

Coelho, A.L.N. 2009. Sistema de Informação Geográfica (SIG) como suporte na elaboração de planos diretores municipais. Caminhos de Geografia, 10(30): 93110.

Dallacort, R., Martins, J.A., Inoue, M.H.; Freitas, P.S.L. \& Krause, W. 2010. Aptidão agroclimática do pinhão manso na região de Tangará da Serra, MT. Revista Ciência Agronômica, 41(3): 373-379.

Devicari, L.F. 2009. Modelo de dissecação do relevo como fator topográfico na equação universal de perda de solo aplicado ao município de São Pedro do Sul - RS. 125p. Dissertação (Mestrado). Centro de Ciências Naturais e Exatas, Universidade Federal de Santa Maria.

EMBRAPA. Empresa Brasileira de Pesquisa Agropecuária. 1999. Centro Nacional de Pesquisa de Solos (Rio de Janeiro, RJ). Sistema Brasileiro de Classificação de Solos. Brasília, DF: Embrapa Produção de Informação, 412p.

Farinasso, M., Carvalho Júnior, O.A., Guimarães, R.F., Gomes, R.A.T. \& Ramos, V.M. 2006. Avaliação qualitativa do potencial de erosão laminar em grandes áreas por meio da Eups - Equação Universal de perdas de solos utilizando novas metodologias em SIG para os cálculos dos seus fatores na região do Alto Parnaíba - PI-MA. Revista Brasileira de Geomorfologia, 7(2): 73-85.

IBGE. Instituto Brasileiro de Geografia e Estatística. 2002. Mapa de Clima do Brasil. Disponível em: $<$ ftp://Geoftp.Ibge.Gov.Br/Mapas_Tematicos/Mapas_Murais/Clima.Pdf>. Acesso em: 13 jan. 2013.

IBGE. Instituto Brasileiro de Geografia e Estatística. 2006. Manual Técnico de Uso da Terra. 2 ed. Rio de Janeiro: IBGE, 91p.

Lopes, H.L., Candeias, A.L.B., Accioly, L.J.O., Sobral, M.C.M. \& Pacheco, A.P. 2010. Parâmetros Biofísicos na Detecção de Mudanças na Cobertura e Uso do Solo Em Bacias Hidrográficas. Revista Brasileira de Engenharia Agrícola e Ambiental, 14(11): 1210-1219.

Machado, C.A. 2012. Desmatamentos e queimadas na região norte do estado do Tocantins. Revista Cami- 
nhos de Geografia, 13(43): 217-229.

Massa, E.M. \& Ross, J.L.S. 2012. Aplicação de um modelo de fragilidade ambiental relevo-solo na serra da Cantareira, bacia córrego do Bispo, São Paulo-SP. Revista do Departamento de Geografia, 24: 57-79.

Nakashima, M.S.R. 2001. Carta de fragilidade ambiental da bacia do rio Keller, Estado do Paraná: subsídio ao estudo dos processos erosivos. Acta Scientiarum, 23, (6): 1547-1560.

Neves, S.M.A.S. 2006. Modelagem de um banco de dados geográficos do Pantanal de Cáceres/MT: estudo aplicado ao turismo. Rio de Janeiro, 284p. Tese de Doutorado, Programa de Pós Graduação em Geografia, Instituto de Geociências, Universidade Federal do Rio de Janeiro.

Oliveira, R.G., Bacani, V.M., Silva, V.R., Cunha, E.R. \& Ferreira E.M. 2012. Análise da fragilidade ambiental da bacia hidrográfica do córrego São João-MS utilizando geoprocessamento. Revista Brasileira de Cartografia, 64: 15-24.

Pessoa, S.P.M., Galvanin, E.A.S., Kreitlow, J.P., Neves,
S.M.A.S., Nunes, J.R.S. \& Zago, B.W. 2013. Análise espaço-temporal da cobertura vegetal e uso da terra na interbacia do rio Paraguai médio-MT, Brasil. Revista Árvore, 37(1): 119-128.

Reis, T.E.S., Barros, O.N.F. \& Reis, L.C. 2004. Utilização de sistema de informações geográficas para obtenção das cartas de solo e de declividade do município de Bandeirantes-PR. Geografia - Londrina,13(1):3-17.

Ross, J.L.S. 1994. Análise empírica da fragilidade dos ambientes naturais e antropizados. Revista Departamento de Geografia, 8: 63-74.

Santos, R.M., Nóbrega, M.T., Paiva, R.G. \& Silveira, H. 2010. Análise da fragilidade ambiental no município de Tamboara - PR: aplicação e estudo comparativo de duas metodologias. Geoambiente, 3(14): 93-120.

Spörl, C. \& Ross, J.L.S. 2004. Análise comparativa da fragilidade ambiental com aplicação de três modelos. Espaço e Tempo, 1(15): 39-49.

Wang, S.Y., Liu, J.S. \& Ma, T.B. 2010. Dynamics and changes in spatial patterns of land use in Yellow River Basin, China. Journal Land use Policy, 27: 313-323.

\section{Man 525}

Editores: Tania Marques Strohaecker \& Maria do

Carmo Lima e Cunha. 